tion of alum-containing vaccines serves to emphasize the need for deep injection, preferably by the intramuscular route for these vaccines (Sauer and Tucker, 1954 ; Burland et al., 1968). Few would disagree with the advisability of discontinuing pertussis vaccination in children who have suffered a severe generalized reaction to a previous dose of the vaccine. In the case of plain vaccine the wisdom of this may have been justified by the finding of a high incidence of generalized reactions to a second dose of antigens in children who reacted to the first. However, with the adsorbed vaccines generalized reactions were mild and infrequent, and recurrent reactions were not common in those infants who had reacted to a first dose of vaccine. The use of such a vaccine could result in fewer children losing the benefits of a full course of pertussis immunization.

Vaccination in almost all the children in this survey caused the appearance of specific agglutinins; in this respect vaccines $B$ and $C$ were superior to $A$. There was considerable individual variation in amounts of specific agglutinins and of bactericidal antibody produced.

\section{Conclusions}

The value of the mouse weight gain test as an indicator of reaction-provoking tendencies in children is again shown, and it is suggested that it should continue to be applied to all vaccines cnntaining pertussis antigen. The addition of aluminium hydroxide as adjuvant to diphtheria, tetanus, and pertussis combined vaccine served to increase antigen potency and significantly reduce the incidence of generalized reactions in children. A reduction by half in the number of pertussis organisms in the adsorbed combined vaccine did not further reduce reactions and therefore served no useful purpose. Vaccines containing aluminium hydroxide are in widespread use for immunization against diphtheria and tetanus, and it is suggested that protection in infancy can best be obtained by using an adsorbed diphtheria, tetanus, pertussis vaccine.

We thank Dr. Sarah Walker, senior medical officer, Maternity and Child Welfare, City and County of Bristol, and members of the staff of the Royal Hospital for Sick Children, Bristol, who assisted in obtaining samples of serum. Mrs. R. McElroy, S.R.N., made the home visits. We gratefully acknowledge the co-operation of Dr. Jean M. Dolby, of the Lister Institute of Preventive Medicine, who carried out the assays for $B$. pertussis antibodies, and Dr. D. L. Hughes, of Glaxo Laboratories, who determined the potencies of the vaccines.

\section{REFERENCES}

Barr, M., Glenny, A. T., and Butler, N. R. (1955). Brit. med. F., 2, 635. Bousfield, G. (1952). Med. Offr, 87, 265.

Burland, W. L., Sutcliffe, W. M., Voyce, M. A., Hilton, M. L., and Muggleton, P. W. (1968). Med. Offr, 119, 17.

Butler, N. R., and Barr, M. (1960). Med. Offr, 103, 41

Butler, N. R., and Barr, M. (1960) (1965). Immunology, 8, 499

Dolby, J. M., and Vincent, W. A. (1965). Immunology, 8, 499.

Haire, M., Dane, D. S., and Dick, G. (1967)
Holt, L. B. (1967). Med. Offr, 117, 153 .

Hopper, J. M. H. (1961). Med. Offr, 106, 241.

Kendrick, P. L., Eldering, G., Dixon, M. K., and Misner, J. (1947). Amer. F. Publ. Hlth, 37, 803.

McFarlan, A. M., Topley, E., and Fisher, M. (1945). Brit. med. F., 2, 205.

Medical Research Council (1956a). Brit. med. 7., 2, 454.

Medical Research Council Committee (1956b). Lancet, 2, 1223

Medicl Reseach Council Committee (1959). Brit. med. 7., 1, 994.

Muggleton, P. W. (1967). Publ. Hlth (Lond.), 81, 252.

Muggleton, P. W. (1967). Publ. Hlth (Lond.

Perkins, F. T. (1967). Med. Offr, 117, 97. (1963). Brit. med. 7., 1, 1573.

Perkins, F. T., Yetts, R., and Gaisford, W. (1963)

Pittman, M. (1951). 7. infect. Dis., 89, 300. Microbiol., 13, 447.
Pittman, M., and Cox, C. B. (1965). Appl.

Preston, N. W. (1965). Brit. med. F., 2, 11.

Sauer, L. W., and Tucker, W. H. (1954). Amer. F. publ. Hlth, 44, 784 United States Government Regulations (1953, 1961). Pertussis Vaccine May 1953, rev. 1961. United States Public Health Service, National Institutes of Health, Bethesda, Maryland.

Wilson, A. T. Henderson, I. R., Moore, E. J. H., and Heywood, S. N. (1965). Brit. med. F., 2, 623 .

\title{
Cyclophosphamide Therapy in the Nephrotic Syndrome in Childhood*
}

\author{
M. W. MONCRIEFF, $\dagger$ B.M., M.R.C.P., D.OBST.R.C.O.G. ; R. H. R. WHITE, $\ddagger$ M.B., M.R.C.P., D.C.H. \\ C. S. OGG§ M.D., B.SC., M.R.C.P. ; J. S. CAMERON,\| M.D., B.SC., M.R.C.P.
}

Brit. med. F., 1969, 1, 666-671

Gummary : Forty-six children with the nephrotic syndrome whose renal biopsy specimens showed minimal changes and whose response to corticosteroid therapy was unsatisfactory were treated with cyclophosphamide. Three patients were completely steroidresistant from the outset and the remainder were steroiddependent. In several patients steroids controlled the condition less effectively with time. Most patients showed signs of steroid toxicity, and growth retardation was striking.

A moderate leucopenia was induced with cyclophosphamide, and treatment was maintained for three to four months in the majority of cases. Thirty-eight children $(83 \%)$ have remained in complete remission off all treatment for periods of 3 to 23 months, 33 after one course of cyclophosphamide and five after a second course. Two other patients who remitted but relapsed later are still on treatment. In only six patients was full remission not obtained, and three of these were steroidresistant from the start. Two died from pneumonia and adrenal failure and four continued to have proteinuria, though in one an impressive reduction occurred.

The results indicate that cyclophosphamide therapy is an effective alternative for nephrotic children with normal glomeruli on light microscopy who develop steroid dependence or resistance, and who exhibit toxic effects of steroid therapy.

\section{Introduction}

It is nearly 20 years since cytotoxic drugs were first used in the treatment of the nephrotic syndrome (Chasis et al., 1949, 1950) but they were soon to be replaced by corticosteroids. Recent

* The content of this paper was presented in summary at the Clinical Meetical Association and the British Paediatric Meeting of the British Medical Association and
Association, Cheltenham, on 26 October 1968.

t Lecturer in Paediatrics and Child Health, Birmingham University.

† Senior Lecturer in Paediatrics and Child Health, Birmingham University ; Honorary Consultant Paediatrician, United Birmingham Hospitals.

Physician in Renal Diseases, Guy's Hospital, London S.E.1.

II Physician in Renal Diseases and Senior Lecturer in Medicine, Guy's Hospital Medical School, London S.E.1. 
follow-up studies, however, have emphasized the limitations of corticosteroid therapy in children. In a five-year follow-up of nephrotic children treated with prednisolone, Arneil and Lam (1966) found that $69 \%$ had been well with no proteinuria for at least three years but that $22 \%$ still had active disease and $9 \%$ were dead. Likewise Cornfeld and Schwartz (1966) reported $65 \%$ of their patients well, $20 \%$ with active disease, and $15 \%$ dead after five years' follow-up. Extending the period of observation, however, they found that many of the children who had had active disease at five years had died during the course of the next few years; thus, 8 to 10 years after onset $67 \%$ were well, $8 \%$ had active disease, and $25 \%$ were dead.

Recognition of the long-term toxic effects of corticosteroids, as well as therapeutic failures, prompted a revival of interest in cytotoxic drugs, while at the same time less toxic orally administered drugs became available. This form of therapy seemed logical in view of the evidence that immune mechanisms were involved in experimental glomerulonephritis (Heymann, 1961), even though unproved in humans. We previously reported our experience with cyclophosphamide and azathioprine in the treatment of patients with severe proliferative glomerulonephritis associated with the nephrotic syndrome (White et al., 1966). While improvement of renal function followed the use of either drug, we were impressed by the speed with which leucopenia could be reversed on withdrawal of cyclophosphamide, compared with the prolonged and occasionally severe marrow depression induced by azathioprine (White, 1967). In this paper we report the results of cyclophosphamide treatment in 46 children with the nephrotic syndrome whose renal biopsy specimens showed "minimal changes" and in whom the results of corticosteroid therapy were considered unsatisfactory.

\section{Material and Methods}

Initially we regarded active disease of many years' duration and steroid resistance as the two main indications for cyclophosphamide therapy. However, as we gained experience with this treatment and became increasingly aware of the satisfactory results obtained we began to treat children whose disease was of shorter duration but who relapsed frequently or remained in remission only at the price of steroid toxicity. The majority of patients were referred by other paediatricians and there was understandably some variation in their management. We have arbitrarily defined a relapse as a recurrence or an increase of proteinuria which, in the opinion of the paediatrician, necessitated a substantial increase in the dose of steroids. This gives only an approximation of the true frequency of relapse as the parents of some patients had themselves increased the dose of steroids at home whenever proteinuria recurred.

Forty-six patients with a minimum follow-up of three months from the last day of cyclophosphamide therapy are included in this report. Clinical data before starting treatment are given in Table I. There were 33 boys and 13 girls. The age of onset of illness ranged from 11 months to 15 years (mean 5 years). The age when cyclophosphamide therapy was started ranged from $2 \frac{1}{2}$ to 17 years (mean 10 years) and the duration of disease from 4 months to 13 years (mean 5 years). All patients had been treated with oral steroids but in addition nine received corticotrophin. Seven of these were given azathioprine and a further child was given mercaptopurine, with benefit in only one, who, however, relapsed subsequently. Prednisone and prednisolone were the corticosteroids used most frequently, but cortisone, triamcinolone, dexamethasone, and betamethasone were occasionally used.

Thirty-five children were in relapse at the time that treatment with cyclophosphamide was started; 28 were on maintenance steroid therapy and seven were off treatment altogether. The remaining 11 patients were in remission but receiving steroids when cyclophosphamide therapy was initiated. Only nine .children had not received corticosteroids continuously during the previous year, and they had had remissions of four to 16 weeks' duration. Seventeen of the children had had more than two relapses per year, 15 had had one or two relapses per year, and 11 had had less than one relapse per year (Table I). Three children showed early resistance to corticosteroids, and seven showed late resistance-that is, they failed to respond to a dose of corticosteroids which had previously induced a remission. The majority of children showed evidence of serious steroid toxicity, and the effect of steroids on growth was striking (Table I). Only three were above the 50th percentile for height, while 17 were below the 3rd percentile.

TABLE I.-Details of Previous Illness and Results of Steroid Therapy in 46 Children with the Nephrotic Syndrome

\begin{tabular}{|c|c|c|c|c|c|}
\hline \multirow{2}{*}{$\begin{array}{l}\text { Case } \\
\text { No. }\end{array}$} & \multirow[b]{2}{*}{ Sex } & \multirow{2}{*}{$\begin{array}{c}\text { Duration } \\
\text { of } \\
\text { Illness } \\
\text { (years) }\end{array}$} & \multirow{2}{*}{$\begin{array}{c}\text { No. of } \\
\text { Relapses* }\end{array}$} & \multicolumn{2}{|c|}{ Steroid Toxicity } \\
\hline & & & & $\underset{\text { percentile }}{\text { Height }}$ & Othert \\
\hline $\begin{array}{l}46 \\
45 \\
44 \\
43 \\
42 \\
41 \\
40 \\
39 \\
38 \\
37 \\
36 \\
35 \\
34 \\
33 \\
32 \\
31 \\
30 \\
29 \\
28 \\
27 \\
26 \\
25 \\
24 \\
23 \\
22 \\
21 \\
20 \\
19 \\
18 \\
17 \\
16 \\
15 \\
14 \\
13 \\
12 \\
11 \\
10 \\
9 \\
8 \\
7 \\
6 \\
5 \\
4 \\
3 \\
2 \\
1\end{array}$ & $\begin{array}{l}M \\
M \\
M \\
F \\
M \\
M \\
M \\
M \\
M \\
F \\
M \\
F \\
M \\
F \\
M \\
M \\
M \\
M \\
M \\
M \\
M \\
F \\
M \\
M \\
F \\
M \\
M \\
F \\
F \\
M \\
M \\
M \\
M \\
M \\
F \\
F \\
M \\
M \\
F \\
M \\
M \\
M \\
F \\
F \\
M \\
M\end{array}$ & $\begin{array}{c}3 \\
4 \\
2 \\
4 \frac{1}{2} \\
7 \\
8 \\
9 \frac{1}{2} \\
5 \\
10 \\
7 \\
7 \frac{1}{3} \\
1 \frac{3}{4} \\
5 \frac{1}{4} \\
7 / 12 \\
13 / 12 \\
7 / 12 \\
13 \\
4 \frac{1}{2} \\
3 \\
7 / 12 \\
2 \\
1 \\
11 \\
5 \\
6 \\
9 \\
8 \frac{1}{2} \\
1 \\
6 \frac{1}{2} \\
13 / 12 \\
5 \\
1 \frac{1}{2} \\
4 / 12 \\
2 \frac{1}{2} \\
10 \frac{1}{3} \\
1 \frac{3}{4} \\
3 \\
3 \frac{1}{2} \\
8 / 12 \\
8 \\
7 \\
78 \\
2 \\
18 \\
9\end{array}$ & $\begin{array}{c}2 ; \mathrm{LR} \\
\text { ER } \\
7 \\
6 \\
>15 ; \mathrm{LR} \\
>10 \\
15 \\
9 \\
8 \\
11 \\
1 ; \mathrm{LR} \\
3 \\
>10 \\
5 \\
4 \\
5 \\
10 \\
5 \\
10 \\
4 \\
8 \\
5 \\
8 \\
19 \\
11 \\
14 \\
7 \\
4 ; \mathrm{LR} \\
6 \\
3 \\
14 \\
5 \\
\text { ER } \\
3 \\
9 \\
5 \\
3 \\
3 \\
4 ; \mathrm{LR} \\
9 \\
6 \\
4 \\
\mathrm{ER} \\
7 ; \mathrm{LR} \\
3 ; \mathrm{LR} \\
12\end{array}$ & 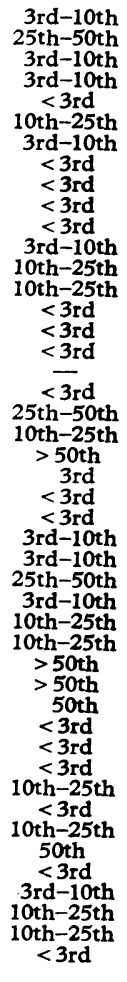 & 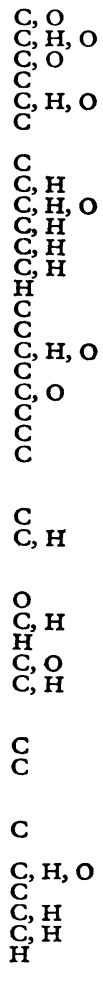 \\
\hline
\end{tabular}

* ER = Early steroid resistance. $\mathrm{LR}=$ Late steroid resistance, after initial response †C $=$ Cushingoid features. $\mathrm{O}=$ Osteoporosis. $\mathrm{H}=$ Hypertension (diastolic B.P.
$90 \mathrm{~mm}$.Hg or more).

Percutaneous renal biopsy was performed in all the children, and examination of the specimens by light microscopy showed either normal glomeruli or mild mesangial hypercellularity in all except two children. We have classified these as "minimal changes." In the two exceptions there were minimal changes with focal glomerular obsolescence. The selectivity of the proteinuria was measured in 36 patients by the methods of either Joachim et al. (1964) or Cameron and Blandford (1966). Thirty-one children had a highly selective proteinuria and five showed slightly reduced selectivity. Serum $\beta_{1 \mathrm{c}}$-globulin levels were estimated in 33 patients by a simple radial diffusion method (Ogg et al., 1968) and were found to be normal.

\section{Treatment}

The basic scheme of treatment has been outlined already (White, 1967). Inpatients were given cyclophosphamide in a dose of $5 \mathrm{mg}$. $/ \mathrm{kg}$./day as a single dose at bedtime. A white blood count (W.B.C.) was performed every one to two days until a leucopenia developed, when the dose of cyclophosphamide was reduced to $2-3 \mathrm{mg}$. $/ \mathrm{kg}$./day and adjusted 
to maintain the total W.B.C. below $4,000 / \mathrm{cu}$. $\mathrm{mm}$. If the total neutrophil count threatened to fall below $1,000 / \mathrm{cu} . \mathrm{mm}$. cyclophosphamide was stopped and later restarted in smaller dosage. Once a stable leucopenia was reached the W.B.C. was checked weekly and the haemoglobin and platelet count were checked periodically. A few children were treated as outpatients with an initial dose of $3 \mathrm{mg} . / \mathrm{kg}$./day, which was increased if necessary until a leucopenia resulted. In most instances treatment lasted between three and four months. Since the responsibility for carrying out treatment was in the hands of several paediatricians, details varied slightly. Parents and older children were warned in advance about the temporary occurrence of alopecia, and a wig was ordered if desired.

Thirty-nine children were still receiving corticosteroids when cyclophosphamide therapy was started. For the purpose of analysis the 46 patients have been divided into three treatment groups: (1) seven patients who were off steroids but relapsed and were treated with cyclophosphamide alone; (2) (a) 11 patients in remission on steroid maintenance therapy and (b) 22 patients in relapse on steroid maintenance therapyall 33 continued to receive the same dose of steroids until a leucopenia was induced by cyclophosphamide; and (3) six patients in severe relapse on steroids, who were initially given an increased dose of steroids in addition to cyclophosphamide.

Patients in groups 2 and 3 who responded to treatment had their steroids progressively withdrawn and finally discontinued under cover of cyclophosphamide therapy.

\section{Assessment of Results}

The response to treatment has been assessed mainly by reference to the clinical state and urinary protein. In most children we did not consider it necessary to make serial blood chemistry measurements once normality was restored following the abolition of proteinuria, or to repeat creatinine clearance estimations where the initial result was normal. The parents of all our patients were supplied with Albustix strip tests and asked to test the urine daily or weekly, according to the presence or absence of proteinuria. Twenty-four-hour urine collections were made at intervals in most cases. A patient in remission was defined as one who was clinically well, with either persistently negative Albustix readings or a urinary protein of less than $100 \mathrm{mg}$./day. The duration of remission has been timed from the last day of cyclophosphamide therapy until the patient was last assessed in October 1968, unless a relapse occurred earlier.

\section{Results}

\section{Response to Treatment}

The duration of cyclophosphamide therapy and the outcome in individual patients are shown in Fig. 1, and the results of treatment are summarized in Table II. Thirty-three children responded to one course of cyclophosphamide and have remained in remission, without treatment, for between 5 and 23 months. A typical response to treatment is shown in Fig. 2.

TABLE II.-Results of Cyclophosphamide Therapy

\begin{tabular}{|c|c|c|c|c|c|c|}
\hline \multirow{3}{*}{ Result } & & \multicolumn{5}{|c|}{ No. of Patients } \\
\hline & & \multirow{2}{*}{ Total } & \multicolumn{4}{|c|}{ Treatment Group } \\
\hline & & & 1 & $2 a$ & $2 \mathrm{~b}$ & 3 \\
\hline 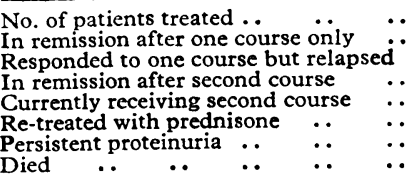 & $\begin{array}{l}\because \\
\because \\
\because \\
\because \\
\because\end{array}$ & $\begin{array}{r}46 \\
33 \\
7 \\
5 \\
1 \\
1 \\
4 \\
2\end{array}$ & $\begin{array}{l}7 \\
5 \\
2 \\
1 \\
1\end{array}$ & $\begin{array}{r}11 \\
9 \\
2 \\
2\end{array}$ & $\begin{array}{r}22 \\
14 \\
3 \\
2\end{array}$ & $\begin{array}{l}6 \\
5\end{array}$ \\
\hline
\end{tabular}

Seven children responded but subsequently relapsed. Five of them relapsed within three months of stopping cyclophosphamide and the other two after six and seven months respectively. Five have completed a second course and have since had protein-free urine for 3 to 13 months; the sixth child is currently receiving a second course of cyclophosphamide, and the seventh was re-treated with prednisone, to which he responded. Four of these seven children received what we now consider inadequate initial courses of cyclophosphamide lasting 2, 3, 7, and 10 weeks respectively, but the remaining three children received 16 or more weeks' treatment.

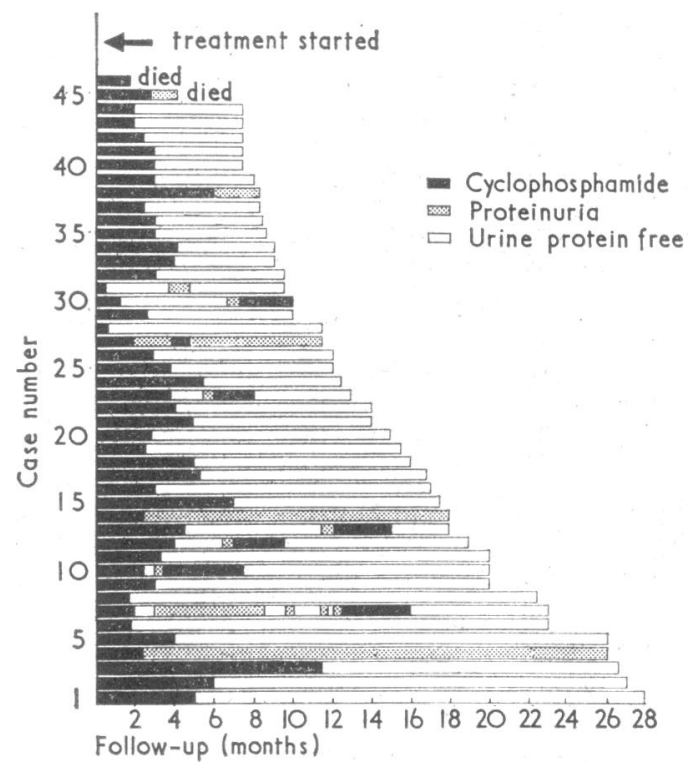

FIG. 1.-Duration of cyclophosphamide therapy and subsequent urinary findings in 46 children with the nephrotic syndrome.

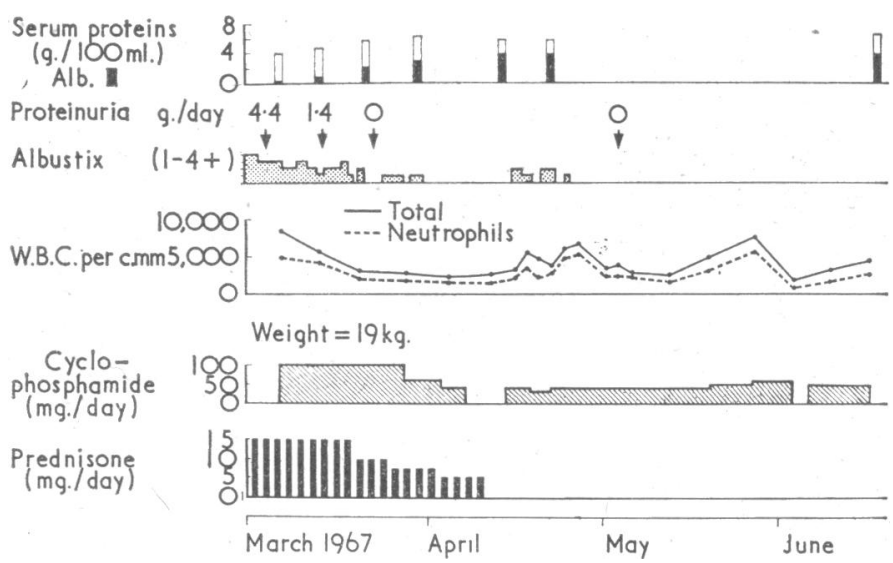

FIG. 2-Case 11. Nephrotic syndrome since July 1965, five relapses. Typical response to cyclophosphamide therapy.

The results of treatment were unsatisfactory in the remaining six patients (Table III). In four children proteinuria persisted. Case 4 was a familial nephrotic with an onset in infancy, whose condition proved resistant to corticosteroids, indomethacin, and azathioprine as well as 10 weeks' treatment with cyclophosphamide. Case 14 did not lose his proteinuria completely, but it decreased from 25 to $1 \mathrm{~g}$. daily. Case 27 received only two short courses of cyclophosphamide, as treatment had to be interrupted owing to ulcerative stomatitis; he developed only transient leucopenia. Case 38 continued to have moderate proteinuria during his six months' treatment with cyclophosphamide, which was combined with prednisolone. The former drug was therefore discontinued while prednisolone was continued in a dose of $10 \mathrm{mg}$./day. Since 
the preparation of Fig. 1, however, his proteinuria has disappeared and prednisolone is being withdrawn gradually.

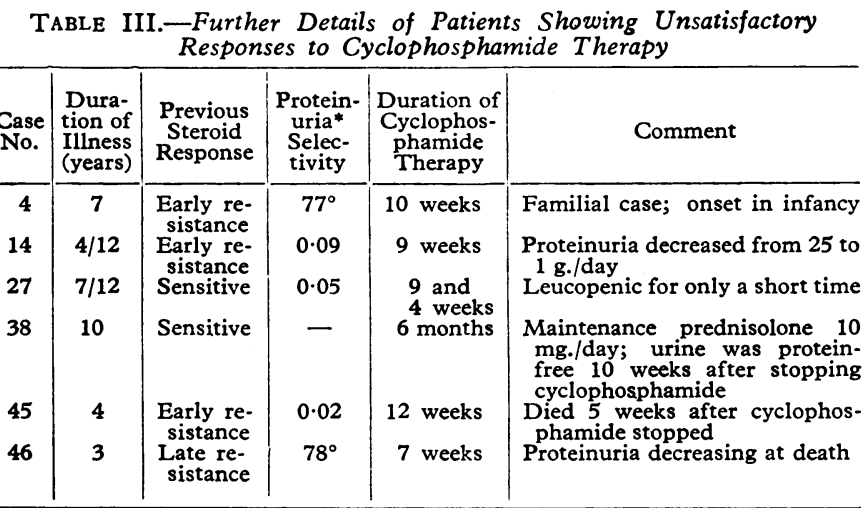

* Figures refer to the angle $\theta$ (Joachim et al., 1964) or the selectivity index (Cameron and Blandford, 1966).

Two children died from adrenal failure and bronchopneumonia. One (Case 45) had completed a course of cyclophosphamide but had not responded. The other (Case 46) was responding with decreased proteinuria and his steroid therapy was being slowly withdrawn. Neither was leucopenic when bronchopneumonia occurred.

From Table III it can be seen that there is no relation between cyclophosphamide failure and the duration of previous disease. Despite the fact that five of the patients had highly selective proteinuria (it was not measured in the sixth), three of them showed early steroid resistance and one late resistance. Only two of these children received three months' or more continuous cyclophosphamide therapy.

\section{Complications of Cyclophosphamide Therapy}

We deliberately aimed to induce a moderate leucopenia (total W.B.C. less than $4,000 / \mathrm{cu}$. mm.) and frequently observed a reduction of lymphocytes to less than $1,000 / \mathrm{cu}$. $\mathrm{mm}$. This was not regarded as a complication, and in no instance was it accompanied by anaemia or thrombocytopenia. The commonest side-effect was alopecia, which affected 36 children (Table IV). However, hair growth invariably recurred, usually after, but sometimes before, completion of treatment. Mild anorexia and nausea were experienced by several children, especially at the beginning of treatment, but were reduced to a minimum by giving cyclophosphamide at bedtime, when antiemetics could also be taken without inconvenience from drowsiness. Severe anorexia and vomiting necessitated interruption of treatment in only two patients. Three children receiving prochlorperazine as an antiemetic developed dystonia, which has previously been described in association with this drug (Cottom and Newman, 1966). Three children experienced transient chemical cystitis during treatment and two developed jaundice, which appeared to be due to infective hepatitis. One child developed aphthous stomatitis, which led to discontinuation of treatment, though at the time he was not leucopenic.

TABLE IV.-Complications of Therapy

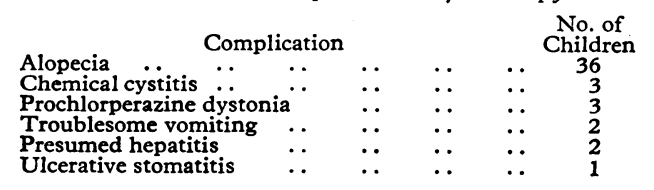

\section{Discussion}

From the follow-up studies of Cornfeld and Schwartz (1966) and Arneil and Lam (1966) it is evident that the ultimate mortality rate of children with the nephrotic syndrome is likely to be in the region of $30 \%$, in spite of steroid therapy. Renal biopsy findings were not reported in their patients, but in our own series of unselected nephrotic children, in contrast with adults (Blainey et al., 1960 ; Cameron, 1968), the incidence of severe proliferative glomerulonephritis is less than $10 \%$, the remainder showing either "minimal changes" or mild proliferative glomerulonephritis (White, 1967 ; Cameron, 1968). It can therefore be argued that up to two-thirds of those who ultimately die have initially mild renal lesions and highly selective proteinuria. Although a few of these patients are steroid-resistant, most are steroid-dependent-that is, they respond to corticosteroids but relapse when treatment is reduced or discontinued, and tend to develop steroid toxicity. They are numerically the greater problem for the practising paediatrician.

Coldbeck (1963) successfully treated five nephrotic children with cyclophosphamide, which he found more effective and less toxic than nitrogen mustard. However, treatment was combined with corticosteroids and in no instance lasted longer than six weeks. The longest follow-up at the time of publication was nine months, but four of the patients were still on steroid therapy. West et al. (1966) gave cyclophosphamide to four children with steroid-resistant nephrosis and to seven who relapsed, achieving remissions of 10 to 49 months in all but one patient. On the other hand, only one out of four with long-standing residual proteinuria responded. Grupe and Heymann (1966) treated nine children, but obtained complete remissions in only four, with reduction of proteinuria in a further two and complete failure in the remaining three. Etteldorf et al. (1967) successfully treated 14 children, though one unfortunately died from varicella and pneumococcal sepsis while still receiving cyclophosphamide.

The cases we have described in this paper represent the hard core of typical nephrotic children, many of whom would doubtless have otherwise continued to have active disease until death. Thirty-eight out of 46 such patients (82.6\%) have responded to treatment with one or two courses of cyclophosphamide and have remained in remission for periods of 3 to 23 months. Clearly judgement must be reserved on those whose remissions at the time of writing have lasted less than six months. Nevertheless, 30 of the 37 children who in the year preceding cyclophosphamide therapy required continuous steroid maintenance therapy are now off all treatment, while eight of the nine who were on intermittent steroid therapy have already been in remission for substantially longer periods than they had during the preceding year.

Our results are comparable to those of West et al. (1966) and of Etteldorf et al. (1967) and superior to those of Grupe and Heymann (1966) (Table V). All three groups permitted a leucopenia of 4,000-5,000/cu. mm. to develop, but West et al. (1966) and Grupe and Heymann (1966) then discontinued treatment, whereas Etteldorf et al. (1967) continued cyclophosphamide therapy until the urine had been protein-free for six weeks, or up to 16 weeks when proteinuria persisted. These workers continued to give their patients steroids for several weeks after completing the course of cyclophosphamide. In fact, Grupe and Heymann (1966) concluded that cytotoxic drugs were ineffective except in combination with steroids, and it is not clear why their results were less satisfactory than those obtained by West et al. (1966), who used a similar therapeutic regimen. In reviewing our own data retrospectively we found it noteworthy that five of the children in whom remissions did not occur received less than three months' treatment with cyclophosphamide (Table III), and we have come to regard this as the minimum lenzth of treatment. Thus cyclophosphamide will almost invariably induce complete remissions in steroid-sensitive patients and those developing late steroid resistance, but not patients who are steroid-resistant from the start. Moreover, the responses shown by patients in groups 1 and 2 suggest that cyclophosphamide acts independently of steroids. 
TABLE V.-Relation Between Duration of Cyclophosphamide Therapy and Resulting Frequency of Complete Remission

\begin{tabular}{|c|c|c|c|c|c|}
\hline \multirow[t]{2}{*}{ Authors } & \multirow{2}{*}{$\begin{array}{l}\text { No. of } \\
\text { Patients }\end{array}$} & \multirow{2}{*}{$\begin{array}{l}\text { No. of } \\
\text { Courses } \\
\text { of } \\
\text { Treat- } \\
\text { ment }\end{array}$} & \multicolumn{2}{|c|}{$\begin{array}{l}\text { Duration of Therapy } \\
\text { (weeks) }\end{array}$} & \multirow{2}{*}{$\begin{array}{l}\text { Complete } \\
\text { Remission }\end{array}$} \\
\hline & & & Range & Average & \\
\hline $\begin{array}{l}\text { West et al. }(1966) \text {.. } \\
\text { Grupe and Heymann (1966) } \\
\text { Etteldorf et al. }(1967) \\
\text { Present series }\end{array}$ & $\begin{array}{r}14 \\
9 \\
14 \\
46\end{array}$ & $\begin{array}{l}17 \\
13 \\
14 \\
51\end{array}$ & $\begin{array}{l}2-8 \\
2-10 \\
7-16 \\
2-50\end{array}$ & $\begin{array}{r}4 \cdot 6 \\
4 \cdot 7 \\
7 \cdot 7 \\
13 \cdot 9\end{array}$ & $\begin{array}{l}73 \% \\
44 \% \\
86 \% \\
83 \%\end{array}$ \\
\hline
\end{tabular}

We have not attempted an evaluation of other cytotoxic drugs in nephrotic children, apart from patients with severe proliferative glomerulonephritis (White et al., 1966). Adams et al. (1967) obtained satisfactory results in two adult nephrotic patients with minimal glomerular abnormalities, using a combination of azathioprine and prednisone, but Sharpstone et al. (1969) had no success with the same treatment. Seven children in the present series received azathioprine and none showed any response to treatment in doses of $2-4 \mathrm{mg}$. $/ \mathrm{kg}$./day. This drug is currently being assessed in a multicentre international trial. Chlorambucil has also been found effective when given alone to steroid-dependent nephrotic children, and, in combination with mercaptopurine or azathioprine, to those with steroidresistant disease (Bariéty et al., 1966 ; Largue et al., 1967).

The mode of action of cyclophosphamide is uncertain. It is highly effective in the treatment of autoimmune glomerulonephritis in NZB $\times$ NZW F1 hybrid mice (Russell et al., 1966 ; Russell and Hicks, 1968). This effect was attributed to the lympholytic action of cyclophosphamide, and it is of interest that many of our patients developed a striking degree of lymphopenia during treatment. However, evidence of an immunological disturbance is lacking in nephrotic children whose renal biopsy specimens show " minimal changes" (Drummond et al., 1966). Cytotoxic drugs based on the purine molecule have also been shown to have an anti-inflammatory action (Page et al., 1962). It is not certain, therefore, whether or not it is necessary to produce a leucopenia, and it is possible that a longer course of treatment with lower dosage might be equally effective.

Minor side-effects are common with cyclophosphamide but do not present insuperable problems. Young children do not mind the alopecia, which generally affects them more severely than adolescents in the dosage we have used. In cases where embarrassment and interference with schooling are anticipated, a wig can be prescribed. New hair often grows curly and may contain blonde streaks initially. One of the two children in whom anorexia and vomiting necessitated interruption of treatment had somewhat exaggerated symptoms during his initial inpatient treatment and it was decided to stop cyclophosphamide after only seven weeks, by which time he was in complete remission. However, he relapsed five weeks later, and after failing to respond to azathioprine and relapsing three more times during the ensuing year he himself requested a further course of treatment. On this occasion he was treated as an outpatient for 14 weeks, with only minimal nausea controlled by cyclizine hydrochloride, and has since been in remission for seven months.

Haemorrhagic cystitis is an infrequent complication, and appears to be due to a direct chemical action of cyclophosphamide metabolites, which are excreted by the kidney (Rubin and Rubin, 1966). It is managed by encouraging a copious fluid intake and frequent voiding of urine. Two children developed jaundice, presumed to be due to infective hepatitis, which has previously been reported by Fernbach et al. (1962) in one out of 44 childrein treated with cyclophosphamide for leukaemia. These may be chance occurrences, though the possibility of impaired immune responses to viruses must be considered, while focal hepatic necrosis has also been reported in mice receiving the drug in huge doses of $5 \mathrm{mg} . / 10 \mathrm{~g}$. body weight, which proved $80 \%$ lethal (Fox, 1964). Etteldorf et al. (1967) reported a death associated with severe varicella infection, but the patient, like our two who developed hepatitis, was also receiving corticosteroids and showed adrenal atrophy at necropsy.

Little is known about the teratogenic hazards of cyclophosphamide, or about its long-term effect on the gonads. Marazzini and Macchi (1966) recorded the birth of normal babies after two pregnancies during which the drug was given for Hodgkin's disease. Greenberg and Tanáka (1964), however, reported the case of a baby born prematurely with absence of both big toes, after a pregnancy in which cyclophosphamide was given in high dosage during the seventh and eighth weeks.

In our experience cyclophosphamide has been remarkably free from serious toxicity. Indeed, we were more impressed by the adverse effects of prolonged corticosteroid therapy, especially on growth, and our aim-which we successfully achieved in most cases-was to discontinue steroid therapy under cover of cyclophosphamide. This has been followed by obvious growth spurts and lessening of obesity in children whom we have followed up for a long enough time. It has been claimed that the use of corticotrophin lessens the risk of adrenal suppression, and it has recently been advocated for children with growth failure (Friedman and Strang, 1966). However, this treatment does not produce more lasting remissions than oral corticosteroids and has the definite disadvantage that it can only be given by injection. Patients in the present series who had received substantial doses of corticotrophin exhibited markedly Cushingoid features.

Our findings indicate that cyclophosphamide is an effective alternative treatment for steroid-dependent nephrotic children and for those who develop signs of steroid toxicity. We do not, however, recommend that this drug should be used as the primary treatment of the nephrotic syndrome, since it may be expected that about $40 \%$ of affected children will respond satisfactorily to prednisone (Arneil and Lam, 1966) without developing signs of toxicity. The difficulty is to judge at an early stage of the illness which patient will ultimately prove steroid-dependent, and this problem requires further study. In the meantime, cyclophosphamide should be reserved for children fulfilling the criteria which we have defined.

We wish to thank the many paediatricians who have referred patients for invesigation and treatment.

ADDENDUM: Since the preparation of this report the condition of two patients has changed. Case 7 (Fig. 1) relapsed seven months after completing his second course of cyclophosphamide ; his response must therefore be classified as " unsatisfactory." On the other hand, Case 14 (Fig. 1, Table III), whose proteinuria diminished but was not abolished during treatment, has now had protein-free urine for three months. The status of the remaining children is unchanged after a further three months' observation. Thus $83 \%$ of patients have been in remission for 3 to 26 months.

\section{REFERENCES}

Adams, D. A., Gordon, A., and Maxwell, M. H. (1967). F. Amer. med. Ass., 199, 459 .

Arneil, G. C., and Lam, C. N. (1966). Lancet, 2, 819.

Bariéty, J., Lagrue, G., Fritel, D., and Milliez, P. (1966). Bull. Soc. méd. Hôp. Paris, 117, 963.

Blainey, J. D., Brewer, D. B., Hardwicke, J., and Soothill, J. F. (1960). Quart. 7. Med., 29, 235.

Cameron, J. S. (1968). Brit. med. 7, 4, 352.

Cameron, J. S. (1968). Brit. med. F., 4, 352.

Chasis, H., Goldring, W. H., and Baldwin, D. S. (1949). Proc. Soc. exp. Biol. (N.Y.), 71, 565 .

Chasis, H., Goldring, W. H., and Baldwin, D. S. (1950). F. clin. Invest. $29,804$.

Coldbeck, J. H. (1963). Med. F. Aust., 2, 987.

Cornfeld, D., and Schwartz, M. W. (1966). F. Pediat., 68, 507.

Cottom, D. G., and Newman, C. G. H. (1966). Arch. Dis. Childh., 41, 551.

mmond, K. N., Michael, A. F.,

(1966), 7. clin., Invest., 45, 620.

Etteldorf, J. N., Roy, S., Summitt, R. L., Sweeney, M. J., Wall, H. P., and Berton W. M.'(1967). F. Pediat., 70, 758. 
Fernbach, D. J., Sutow, W. W., Thurman, W. G., and Vietti, T. J. (1962). F. Amer. med. Ass., 182, 30.

Fox, M. (1964). Transplantation, 2, 475.

Fox, M. (1964). Transplantation, 2, 47.

Graenberg, L. H., and Tanáka, K. R. (1964). F. Amer. med. Ass., 188, 423.

Grupe, W. E., and Heymann, W. (1966). Amer. f. Dis. Child., 112, 448 Heymann, W. (1961). F. Pediat., 58, 609.

Joachim, G. R., Cameron, J. S., Schwartz, M., and Becker, E. L. (1964). 7. clin. Invest., 43, 2332.

Lagrue, G., Bariéty, J., Canlorbe, P., Vassal, J., and Milliez, P. (1967). Presse méd., 75, 1773.
Marazzini, F., and Macchi, L. (1966). Ann. Obstet. Ginec., 88, 825.

Ogg, C. S., Cameron, J. S., and White, R. H. R. (1968). Lancet, 2, 78. Page, A. R., Condie, R. M., and Good, R. A. (1962). Amer. F. Path. $40,519$.

Rubin, J. S., and Rubin, R. T. (1966). 7. Urol. (Baltimore), 96, 313.

Russell, P. J., and Hicks, J. D. (1968). Lancet, 1, 440.

Russell, P. J., Hicks, J. D., and Burnet, F. M. (1966). Lancet, 1, 1279.

Sharpstone, P., Ogg, C. S., and Cameron, J. S. (1969). In preparation.

West, C. D., Hong, R., and Holland, N. H. (1966). F. Pediat., 68, 516.

White, R. H. R. (1967). Proc. roy. Soc. Med., 60, 1164.

White, R. H. R., Cameron, J. S., and Trounce, J. R. (1966). Brit. med. 7., 2,853 .

\title{
Adverse Effect of Topical Fluorinated Corticosteroids in Rosacea
}

\author{
IAN SNEDDON,* M.B.: F.R.C.P.
}

[With Special Plate facing Page 670]

Brit. med. F., 1969, 1, 671-673

\begin{abstract}
Summary : Fourteen patients suffering from rosacea treated by prolonged topical applications of fluorinated steroids showed adverse effects. Aggravation and extension of telangiectasia occurred in all, and in most cessation of the treatment was followed by severe rebound inflammatory oedema and acute pustular eruption. The telangiectasia cleared or was much improved within three months of cessation of the use of fluorinated steroids. Hydrocortisone did not produce the same effect, and hence it was used, together with oral tetracycline, for treatment.
\end{abstract}

\section{Introduction}

Corticosteroid applications have been so successful in the control of inflammatory reactions of the skin that they are now widely used as a panacea for all dermatoses, but only rarely do undesirable effects occur. Last year I drew attention to an unusual adverse effect of the more potent steroid creams, when used in the treatment of rosacea (Sneddon, 1968). It appeared that prolonged use did suppress pustule formation but increased the telangiectatic appearance of the skin. If the local applications were stopped the pustules recurred rapidly, of ten accompanied by oedema of the face. Many patients resumed treatment to suppress this undesirable effect and thus became virtually dependent, being frightened to stop using the preparations. The appearance of rosacea treated with Betnovate (betamethasone 17-valerate) and Synalar (fluocinolone acetonide) has become a familiar sight, and it is the object of this paper to describe the clinical features and response to treatment of 14 patients seen in the past year.

\section{Case 1}

A 46-year-old housewife complained of a burning and redness of the face of three years' duration. The eruption, which was pustular at the onset, was rapidly controlled by betamethasone ointment that she had applied twice daily for the whole three years. In recent months the skin had become tender, and bleeding followed brisk rubbing with a towel. Examination in January 1968 showed a diffuse erythema and telangiectasia over the whole face right up to the hair margin. It extended far more peripherally than rosacea usually does. The facial skin appeared thinned, atrophic,

* Physician, Rupert Hallam Department of Dermatology, Royal Infirmary, Sheffield. and felt somewhat velvety; a number of small subcutaneous haemorrhages similar to senile purpura were present on the forehead and cheeks. Tetracycline $250 \mathrm{mg}$. twice daily was prescribed and ung. aquosum substituted for the ung. betamethasone. A week later her face became painful and oedematous, but she was encouraged not to resume the betamethasone and to persist with the treatment advised. Tetracycline was continued in a dose of $250 \mathrm{mg}$. twice daily for two months and once daily for a further three months, at the end of which time the facial skin appeared normal.

\section{Case 2}

A housewife aged 40 had treated a facial rash for six years with ung. fluocinolone applied daily. She had tried to stop using it, but the rash, consisting of pustules, recurred within a few days and she felt compelled to use the application again. When first seen in 1968 she showed skin-coloured papules over the forehead, cheeks, and chin, characteristically the abortive papulo-pustules of rosacea, and extensive telangiectasia over the whole forehead, cheeks, and chin. There was a fine downy growth of hair, particularly on the cheeks. The skin appeared thinned, and a number of subcutaneous haemorrhages were present. The eruption was confined to the face and ceased below the angle of the jaw (Special Plate, Figs. 1 and 2). A biopsy specimen taken from the forehead showed normal epidermis. In the dermis sebaceous glands were prominent and surrounded by inflammatory cells, and, in addition, the dermal collagen showed basophilic degeneration with heavy positivity on elastic staining. Dermal vessels were prominent and dilated. The appearances were those of acne rosacea with dermal atrophy.

She was treated with tetracycline $250 \mathrm{mg}$. twice daily for one month and then once daily for a further three months, by which time her face appeared normal (Special Plate, Figs. 3 and 4). During the first two weeks of treatment she complained bitterly that her face had become more painful and swollen. Hydrocortisone ointment was prescribed as a substitute for the fluocinolone, as experience had shown that this did not perpetuate the atrophy.

\section{Case 3}

A 34-year-old married bus conductress had controlled a facial eruption with betamethasone ointment for five years. The eruption was described as erythematous with recurrent pustulation. As her face had become more and more telangiectatic she was referred to the dermatological department, where she was seen in March 1968 and advised to stop using the betamethasone ointment. She was admitted to hospital seven days later because the whole of her face and neck had become red, swollen, and covered with pustules, 2 to $3 \mathrm{~mm}$. in diameter. The pustules extended over the whole face to the hair margin, down the sides of the neck, and on to the pinnae 